\title{
DO CAMPO DO VISÍVEL E INVISÍVEL À PERFORMANCE DE CURA ESPIRITUAL: UM ENSAIO ANALÍTICO SOBRE ATENDIMENTOS DE UMA PAJÉ CABOCLO EM SANTARÉM/PA
}

\author{
FROM THE FIELD OF THE VISIBLE AND INVISIBLE \\ TO THE PERFORMANCE OF SPIRITUAL HEALING: AN \\ ANALYTICAL ASSAY ON THE SERVICE OF A CABOCLO \\ PAJE IN SANTAREM/PA
}

\section{Dárnisson Viana Silva}

darnissonviana@yahoo.com.br

Doutor em Ciências Sociais Universidade Federal de Campina Grande/PB

Orcid: https://orcid.org/0000-0003-3395-5279

\section{RESUMO}

Este artigo resulta da preocupação de abordar o tema da performance em práticas de interação social, pensado inicialmente para uma disciplina de curso de doutorado intitulada "Antropologia e Performance" no ano de 2016. Posteriormente, a partir de dados de campo na região do Baixo Amazonas, no final do mesmo ano, houve o interesse de produzir alguns insights sobre as intersecções do conceito com outras dimensões do vivido nas interações sociais produzidas em contextos de práticas de "cura espiritual". Para tanto, analisamos o caso de uma pajé caboclo num sítio urbano do município de Santarém, no oeste do Estado do Pará, através de abordagem etnográfica, descrição de relatos e consultas pessoais. No transcorrer da análise foram elaboradas reflexões com contribuições da fenomenologia de Merleau-Ponty (1908-1961) e dos estudos em performance focando os aspectos ritualísticos da ação. Assim, buscou-se identificar alguns operadores performativos no atendimento de pessoas que recorrem a esses conhecimentos tradicionais de cura, bem como avaliar em que medida se estabelece conexões com a eficácia terapêutica ali investida. Em uma consideração ensaística foi possível verificar modelos de persuasão próprios da cultura da pajelança cabocla onde o que identificamos como performance de cura cumpre papel fundamental nos processos de cura espiritual.

Palavras-chave: performance de cura; visível e invisível; pajelança cabocla.

\begin{abstract}
This article is the result of a concern to address the theme of performance in practices of social interaction, initially thought for a doctoral course discipline entitled "Anthropology and Performance" in 2016. Subsequently, from field data collected in the region of Baixo Amazonas, at the end of the same year, there was interest in producing some insights into the intersections of the concept with other dimensions of the lived in social interactions produced in contexts of "spiritual healing" practices. To this end, we analyzed the case of a caboclo shaman in an urban site in the municipality of Santarém, in the west of the State of Pará, through ethnographic approach, description of reports and
\end{abstract}


personal consultations. During the analysis, reflections were elaborated with contributions from the phenomenology of Merleau-Ponty (1908-1961) and from studies in performance focusing on the ritualistic aspects of action. Thus, we sought to identify some performative operators in the care of people who resort to this traditional knowledge of healing, as well as assessing the extent to which connections are established with the therapeutic efficacy invested there. In an essayistic consideration, it was possible to verify models of persuasion typical of the culture of caboclo shamanism where what we identified as healing performance plays a fundamental role in the processes of spiritual healing.

Keywords: healing performance; visible and invisible; caboclo shamanism.

\section{INTRODUÇÃO}

Estudos antropológicos sobre a temática performance, nas últimas duas décadas, têm apontado para um quadro diverso de abordagens que extrapolam a própria disciplina acadêmica. Existem diferentes maneiras pelas quais a vida social e o comportamento humano individual e coletivo podem ser vistos "como" e "enquanto" performances (BAUMAN, 1975; SCHECHNER, 2006, 1985; GOFFMAN, 1959, 2011). Dentro de um amplo espectro de objetos de análise, o campo da religiosidade e do mágico-religioso tem se colocado como registro fecundo de observação para as ciências sociais com estas preocupações e, em especial, para a própria Antropologia.

Uma das questões que sugeriu um olhar mais atento de nossa parte, dentro desse movimento, foi a vinculação do que se entende atualmente por estudos de performance, mais notadamente a performance cultural ou ritual e sua possível correlação com a eficácia terapêutica produzida em pessoas que recorrem aos conhecimentos tradicionais de cura, através de especialistas conhecidos como xamãs, curandeiros ou pajés (sacacas), quer seja na cidade, quer seja em comunidades rurais mais afastadas.

É sabido que vasta literatura tem se debruçado sob os aspectos da eficácia "simbólica" no tratamento de enfermidades que acometem indivíduos de sociedades indígenas, comunidades tradicionais e pessoas comuns em diversas partes do mundo. Alguns destes estudos focalizam a desenvoltura das autoridades de cura de cada grupo analisado, tentando produzir, cada vez mais, esclarecimentos sobre as relações sociopolíticas, cosmológicas e intercambiais aí implicadas (ANDRADE, 2019; DE LIMA, 2019) ou até mesmo hibridizações impulsionadas por novas configurações históricas vivenciadas no campo do religioso e no campo das crenças.

Cada vez mais, cresce o número de pesquisas que privilegiam a análise da transnacionalização de igrejas ou de apropriações locais de práticas espirituais oriundas de diversas partes do mundo e que se prestam a hibridizações ou rearranjos criativos. Essas pesquisas apontam para 
aquilo que Otávio Velho (1997) diz ser "os efeitos do desaparecimento de fronteiras simbólicas rígidas entre diferentes campos religiosos, entre campo religioso e campo mágico e esotérico, entre religião e novas crenças (SILVA; GRÜNEWALD, 2019, p. 200).

No que diz respeito ao modo de vida na cidade e paralelamente a legitimidade da medicina moderna ocidental, as práticas de cura de origem indígena, ou em nosso caso mais específico "caboclo amazônico", ainda operam formas significativas de se relacionar com a saúde e a doença daqueles que, acometidos por alguma aflição (física ou espiritual), buscam formas alternativas de atendimento. Ainda hoje, é de costume entre as pessoas mais idosas no vale do Amazonas e em várias outras partes do Brasil recorrerem às rezadeiras e benzedeiras para resolver infortúnios de natureza física (dor de cabeça, dor no corpo, febres, dores estomacais, picadas de cobras, abertura do útero, dentre outros) ou de ordem espiritual (mau-olhado, inveja, atrair sorte, dinheiro e desfazer-se de feitiços ou judiarias).

Sem dúvida, há uma dimensão visível nos conhecimentos corporificados ou como sugere Diana Taylor (2013) nas embodied practices de representantes destas práticas culturais, como as "mestras de ofícios tradicionais", assim designada por Ferreira (1996), que sinalizam para espaços de performance nos seus atos de cura. Desse modo, Cunha e Assunção (2013) destacam que,

não existe benzedeira que execute seu oficio em silêncio. $\mathrm{O}$ ato de proferir a reza se faz presente e se performatiza no instante, sendo estas conhecedoras e executoras, em que visível e invisível irão compor a força das palavras das benzedeiras no ato de cura. Poder tão grande, que em sua humildade, é atribuído por elas à fé naquelas palavras em forma de preces, aliada a ramos e outros itens envolvidos utilizados para curar enfermidades diversas (CUNHA; ASSUNÇÃO, 2013, p. 3, grifo nosso).

Podemos, assim, observar diversas técnicas utilizadas por um corpo de especialistas populares (erveiras, raizeiros, benzedeiras, parteiras) envolvidos com práticas curativas na região delimitada para o estudo. Saberes estes que vão desde a manipulação de plantas medicinais, animais medicinais, rezas, técnicas de massagens (para "desmentiduras"), defumações e receitas de banhos prescritas com procedimentos específicos e minuciosos, pois, para cada suplicante um "passo a passo" é indicado.

Em várias regiões do estado do Pará, observamos a incidência de outro especialista de cura denominado por muitos (nativos e não nativos) de "pajé" ou de "xamã". Geralmente, são senhores ou senhoras que segundo os relatos adquirem o "dom divino" desde criança e que com o decorrer do tempo vão sendo iniciados por outros curandeiros ${ }^{1}$ mais experientes e, assim, se aprofundam no conjunto de saberes voltados a prática de cura e aconselhamentos. Como bem lembra Maués (1990, 2002b, 2014), a expressão "pajé" (há quem faça a designação de 
pajoa para mulheres que possuem estes dons) tem origem na língua tupi e consideramos apropriado usar aqui o termo pajé caboclo por se fazer referência aos pajés que realizam seus "trabalhos" ou sessões xamânicas incorporados de entidades caboclos em seus respectivos sítios (tendas/ malocas/casas) de atendimento. Para levar adiante estas considerações é preciso estar a par, através das palavras do eminente antropólogo paraense, de informações e alguns elementos introdutórios deste universo denominado de pajelança.

Os primeiros estudos sobre aquilo que denomino de pajelança cabocla foram feitos por folcloristas, do final do século XIX. A dissertação de mestrado, mais tarde publicada em livro, do historiador Aldrin de Moura Figueiredo, conta-nos esta história: buscando investigar e analisar a constituição do campo de estudos sobre pajelança cabocla na Amazônia, Figueiredo vai buscar as notas e a bibliografia utilizada por Eduardo Galvão em seu livro Santos e Visagens (Galvão, 1955). Esses folcloristas são os pioneiros em que se inspirou Galvão para traçar o mapa da pajelança como parte da "religião do caboclo amazônico". Há todo um mapa cognitivo construído por esses personagens, que constitui um conjunto de crenças e práticas em que estão mescladas antigas tradições de origem tupi, com elementos fundamentais do catolicismo de fontes ibéricas e medievais trazido pelos portugueses e, também, alguns traços de concepções e práticas de raiz africanas, bem como traços nos quais se pode notar em anos mais recentes uma leve ou mais acentuada influência Kardecista. Não se trata, evidentemente, de uma igreja ou seita: é um culto xamânico que possui, sobretudo, finalidades terapêuticas (MAUÉS, 2014, p. 200).

Segundo Boyer (1999), em relação a pajelança cabocla e dependendo da região do culto de possessão, os espíritos caboclos podem fundir diversas categorias de entidades (femininos ou masculinos), como no caso da cidade de Belém (PA) ou, por exemplo, no município de Autazes (Amazonas) estudado por Scopel (2007). Porém, não é nosso propósito aprofundar a compreensão destas relações no âmbito da mediunidade, mas nos interessa os operadores performáticos emoldurados nas práticas dos pajés caboclos, que ao atenderem os seus consulentes tendem a "amarrar indivíduos a uma economia de olhares e do olhar" (TAYLOR, 1997), bem como os desdobramentos terapêuticos ali expressos. Pois, afinal, "toda sessão realmente xamânica acaba por ser um espetáculo sem igual no mundo da experiência cotidiana” (ELIADE, 1998, p. 554).

A hipótese a ser analisada sugere que há uma vinculação direta, aparentemente contraditória, entre o visível (o mundo ordinário)

174 e o invisível (o mundo oculto), e que na maioria dos casos o sucesso do tratamento espiritual depende da interdependência dessas duas categorias, uma vez que se acredita que o mundo invisível pode interferir no mundo visível. Muitos outros pesquisadores, índios e não índios, chamam atenção para as dimensões do visível e do invisível como centralidade para compreender os procedimentos (cosmológicos) 
xamânicos em muitas partes das américas (BOYER, 1999; KOPENAWA; ALBERT, 2016; LANGDON, 2001; 2016; MAUÉS, 2014). O nosso caso abordado, neste sentido mais amplo, não difere.

Por outro lado, entendemos que na discussão das qualidades multivocais do conceito/termo performance (que é basicamente do campo do visível-expressivo) há um vasto campo de linhas interpretativas e metodologias de investigação que diferem de acordo com cada propósito, mas que ainda assim comungam de objetivos comuns. Nesta encruzilhada de buscas, como prescrevem Langdon e Hartmann (2020), as análises de performance têm ganhado importante peso na produção antropológica brasileira ${ }^{2}$ nas últimas décadas e postulam um certo status de "programa de pesquisa" na produção recente do país.

Atualmente, a antropologia da performance no Brasil pode ser considerada um campo consolidado, apesar de sua diversidade interna, e é melhor abordada como um "programa de pesquisa". Conceito desenvolvido pelo filósofo da ciência Imre Lakatos (1970), o programa de pesquisa pressupõe que uma comunidade científica partilhe de um conjunto comum de teorias, métodos e técnica (HARTMANN; LANGDON, 2020, p. 2).

As autoras levantam ainda a conjectura de uma "virada performativa" (CONQUERGOOD, 1989; DAWSEY, 2016) nas preocupações e nas transformações do campo da disciplina no Brasil entendendo que,

na encruzilhada (lugar de cruzamentos, influências, divergências, cisões, fusões, rupturas, multiplicidades) entre Antropologia e formas expressivas em performance, danças, cantos, músicas, narrativas, jogos, brincadeiras, procissões, dramatizações, festas e festivais, manifestações sociais e políticas, rituais de vida e de morte recebem especial atenção, não apenas pelas interpretações ou pelas leituras do social que possibilitam, mas, sobretudo, pelos aspectos simbólicos, expressivos, poéticos, estéticos, politicos e reflexivos que evocam e que produzem (HARTMANN; LANGDON, 2020, p. 2, grifo nosso).

Buscando acompanhar a relevância do número crescente de estudos neste âmbito de preocupação, no presente artigo optamos por chamar de performance a partir das concepções de Richard Schechner (2006), do qual performances marcam identidades, dobram o tempo, remodulam o corpo, adornam o corpo e contam estórias. Segundo essa visão as performances (de arte, rituais, da vida cotidiana) são "comportamentos restaurados", ou seja, comportamentos duas vezes experienciados e que, portanto, para realizá-los as pessoas treinam, ensaiam, se preparam. Nas palavras do autor,

O comportamento restaurado é o processo principal de todos os tipos de performance, seja na vida cotidiana, na cura, nos ritos, em ações, e nas artes. O comportamento restaurado está "lá fora", aparte do "eu". Colocando em palavras próprias, o comportamento restaurado "sou eu me comportando como se fosse outra pessoa", ou "como me foi dito 
para fazer", ou "como aprendi". Mesmo se me sentisse completamente como sou, atuando independentemente, apenas um pouco de investigação revelaria que as unidades de comportamento que contém meu "eu” não foram por "mim" inventadas. Ou, bastante ao contrário, posso experimentar ser "além do que sou", "não eu mesmo" ou "dominado" em transe" (SCHECHNER, 2006, p. 34, grifo nosso).

Portanto, o que pretendemos chamar de performance de cura no caso aqui expresso são as ações restauradas/reiteradas ${ }^{3}$ - ações que moldam comportamentos marcados, enquadrados ou elevados, à parte do só "viver a vida" (SCHECHNER, 2006) - de "autoridades de cura" em diferentes situações de consulta e enfatizamos, como tal, a receptividade e legitimidade construídas perante comunidades e plateias (em geral os consulentes). Adotada esta perspectiva analítica, nos alinhamos aos pressupostos deste autor, um expoente da antropologia da performance, dentre outros, para pensar como a experiência em relevo e outros elementos essenciais da performance, neste caso a performance de cura, podem contribuir na eficácia sui generis da ação social em tela. De modo que discutiremos estes aspectos nos seus pormenores mais adiante.

As ideias aqui suscitadas são desenvolvidas a partir de experiência vivenciada in loco e baseadas em consultas pessoais com uma "pajé" no perímetro de um bairro de periferia da cidade em foco, alternando relatos de consulentes atendidos, análise dos dados descritivos e literatura existente sobre outras regiões. O estudo abrange algumas experiências de atendimento em Santarém/PA, mas traz implicitamente em seu bojo outras experiências vivenciadas a partir de estudo de doutorado recente do autor, no qual foram analisadas categorias de visão de mundo de pescadores ribeirinhos que residem numa zona periurbana da mesma cidade. Tais categorias de visão de mundo fazem parte de uma herança histórico-cultural de índios e caboclos da Amazônia como defendido na tese $e^{4}$ e que ensejam um rico universo de práticas, crenças e aspectos cosmológicos prenhes de significação.

\section{ITINERÁRIOS E PALCOS}

Em uma conferência realizada na Pontifícia Universidade Católica do Rio Grande do Sul, no ano de 2011, o antropólogo britânico Tim Ingold destacou uma reflexão a respeito de como a maior parte das ciências da mente e da cultura, tais como a psicologia e a antropologia, tem seguido as tendências de um pensamento herdado do filósofo Francis Bacon (1561-1626), que a todo custo tenta separar a "realidade" (o mundo "em si", a natureza que pode ser descoberta somente por meio da investigação científica) da "imaginação" (ignorância da ciência e de seus métodos) em dois domínios totalmente exclusivos.

O problema suscitado pelo autor de modo provocativo foi, justamente, como alcançar um ponto de acomodação para os dois 
domínios uma vez que "não se trata de como reconciliar os sonhos da nossa imaginação com os padrões do mundo, mas de como separálos, antes de qualquer coisa" (INGOLD, 2012, p. 17, grifo nosso). Do ponto de vista filosófico, evidentemente, muito antes de Ingold, o filósofo Merleau-Ponty (1908-1961) escreveu uma série de ensaios na década de 1950, com o objetivo de realizar uma crítica a "filosofia do entendimento" sob a qual erige uma nova ontologia da natureza, que não mais condiz com "as ontologias do algo", mas que está envolvida com um conhecimento introdutório ao que ele chamou de uma autêntica ontologia (MERLEAU-PONTY, 2000). Sua preocupação central estava em dissolver a antinomia realismo/idealismo fundada na ideia do ser como "plenitude absoluta" ou "infinita positividade" e que, segundo a qual, o ser ou bem comporta tudo ou então não é nada. Dessa forma, o pensador procede com a intenção de "radicalizar a crítica às categorias com as quais a ciência e a filosofia haviam se acostumado a pensar a natureza: a identidade, a causalidade, a sucessão e o espaço homogêneo" (MARTINS, 2010, p. 472).

Refletindo sobre essa discussão da condição de espessura e profundidade dos seres, segundo Merleau-Ponty (1984), com o propósito de devolver à natureza as "graduações" e "pluralidade de planos", é que podemos adentrar o espaço do invisível e do visível e buscamos compreender alguns operadores nos processos de "cura espiritual”, através de sessões com uma pajé caboclo. Procedemos, todavia, a partir de uma postura entrecruzada que vai desde um posicionamento intelectivo a sensorial corpóreo, de observaçãoparticipante a participação-observante (DURHAM, 1988), de etnógrafo/ antropólogo a consulente/paciente.

Assim, analisando um contexto cultural específico, buscamos refletir criticamente a despeito da "tendência cultural ocidental de compartimentar a experiência e reificar categorias como religião e medicina" (CSORDAS, 2008 p. 30), espiritualidade e ciência. "Cada categoria difunde sua própria ciência, a qual pretende, pois, assumir que o seu campo de conhecimento é analiticamente distinto de todos os outros" (CSORDAS, 2008 p. 30). Nesse sentido, nosso itinerário se deve, nesta empreitada singular, a múltiplos agenciamentos e situações concretas de busca como necessidades acadêmicas, inquietações pessoais, mudanças de planos e insights teóricos.

Uma primeira aproximação com o objeto de reflexão deste artigo remete a curiosidades despertadas durante pesquisa de mestrado voltado ao tema da espetacularização de festas religiosas em comunidades rurais amazônicas, que resultou em uma dissertação e um artigo publicado na Revista Amazônica da Universidade Federal do Pará. Em trabalho dissertativo, chamamos atenção para o fato de como pode ser promissor, em termos de interpretação socioantropológica, apreender o universo mítico que opera significações simbólicas e materiais na 
vida de boa parte das pessoas que ali se encontram, implicando num ordenamento do sistema de crenças e condutas que tem peso valorativo na compreensão do seu mundo social.

Uma das situações descritas na dissertação tem a ver com uma "mãeavó" que levava costumeiramente seu "filho-neto" (na época a criança tinha apenas sete anos de idade) a uma pajé na cidade de Santarém para benzer e tratar de doenças recorrentes. O prestígio que a senhora pajé adquiriu perante a mãe, em detrimento do atendimento médico na unidade de saúde da comunidade, representou o primeiro passo para investigações que, hoje, desejamos compreender mais a fundo.

Ao retornar a Vila/Distrito do município abordado, no ano de 2016, nossos interesses pela mística de cura que circundava a atmosfera cultural local se intensificou e caminhos foram sendo trilhados em direção às práticas de curas xamânicas.

O relato de cura de "Dona Braba"5 (mãe-avó e moradora do Distrito) é ilustrativo de como os eventos e trocas de informações foram formando os fios condutores da busca do antropólogo pela "cura espiritual" enquanto objeto científico e experiência vivenciada.

O menino, "Seu D", sofria de uma canseira! Era uma tosse, era uma tosse, era uma tosse com uma falta de ar que dava medo, quando via... ele tava hãhã... puxando o ar... aquilo vinha de noite nele... ele ficava com isso aqui curvado [apontando para a costela] o avô dele puxava o peito... puxava as costas... e nada! O menino dizia vovó eu não quero morrer! Vovó eu não quero morrer! Eu ficando desesperada disse para o avô dele: - Bóra levar esse menino pra tratar! Bóra levar que esse menino pode morrer por nós e vai fazer uma falta danada, pelo amor de Deus! Quando foi no outro dia fumo batê lá na "Dona Belezura", tomemo o ônibus às oito horas quando foi às nove e meia nós já estávamos lá... Cheguemos lá ela pediu para aguardar que ela ia chamar, quando foi nossa vez eu cheguei e expliquei tudinho o que estava acontecendo, disse tudinho a ela, Tintim por tintim...ela olhou, fez umas perguntas, e disse: - Olhe "Dona Braba"! Seu neto está doente, mas não se preocupe...a senhora tem fé? Se a senhora tiver fé em Deus ele vai ficar bom...vamos ver aqui o que aparece pra nós pra cuidar desse menino. Ela pegou aquele copinho dela mexeu pra lá mexeu pra cá, anotou o nome dele num papelzinho...tudo bonitinho, acendeu aquele cigarrinho dela, que eles tem um cigarro, assim "Seu D", sabe? Que solta aquela fumaça forte... [imitando o trago do cigarro] aí ela assoprou assim dentro do copo.... Quando ela assoprou "Seu D" não demorou muito boiou aquilo dentro do copo...um negócio branco no meio...um pedaço de alguma coisa... aí "Dona Belezura" disse assim: - Olha seu neto tem cura! O problema dele é simplesmente um resto de parto. Está vendo isso aqui no copo? É isso aqui o problema dele. A senhora vai fazer o seguinte! Do mesmo jeitinho que eu vou dizer..., mas eu vou anotar para a senhora não esquecer. Vai comprar uma vela "sebo de Holanda", vai amassar a cera deixar ela bem amassadinha, depois vai comprar uma Buchinha- do-norte6 (luffa operculata), essa buchinha a senhora vai cortar em cruz, 
quatro pedacinho miudinho, porque ela é forte! Tem que ser miudinho e vai ferver numa vasilha pequena até a água pegar cor... quando a água pegar cor ... coloque num frasquinho desses conta-gotas... a cera a senhora misture um pouquinho com o chá da buchinha e passe nessa parte do rosto dele fazendo este movimento [no dorso do nariz até a testa, de cima para baixo] quando for de noite quando ele estiver dormindo a senhora pinga duas gotinhas dentro do nariz dele, pronto! Toda noite a senhora vai fazer a mesma coisa até sair de dentro dele este resto de parto, é isso aqui que vai sair [apontando para o copo], veja bem! E ele vai ficar curado em nome de Jesus...Tá! E depois retorne aqui... [uma pausa na fala e um olhar expressivo] Quando foi no outro dia "Seu D”! Me alembro direitinho como se fosse hoje, o menino ia saindo com a mochilinha dele nas costas pra escola, que ele botou assim a mochila nas costas, ele deu aquele espirro, que parecia quando a gente assopra uma bola de chiclete, "flup"! E saiu aquela coisa branca junto com o catarro que ele gritou vovó me acuda! Eu rápido tirei aquele negócio, Juro por Deus “Seu D”! Do mesmo jeitinho que ela falou, que eu vi boiando no copo dela ["Dona Belezura"] aquela coisa branca igual quando a gente assopra uma bola de chiclete, "flup"! Foi assim que ele foi curado... É por isso "Seu D" que eu acho ela muito Boa! Eu já tinha levado ele no "Seu Conhecido", levei no "Seu Pedroca"... "Seu Conhecido" disse que ele era acompanhado de um espírito já que num deixava ele ficar bom, "Seu Pedroca" disse que era uma asma que não curava, mas "Dona Belezura" disse simplesmente que era um resto de parto, por isso que eu confio nela, ta aí ó curado, cadê? Nunca mais teve nada! Ela já curou tanta gente! Foi minha sobrinha... foi comadre que tava com uns problema no casamento dela, Foi aquela fulana que vem aqui em casa que também uns tempo não tava boa ...foi assim...eu tenho até que voltar lá pra levar uma garrafa de mel que ela me pediu...ó....não posso nem me esquecer (Dona Braba, agosto de 2014).

O relato acima pode incitar diferentes interpretações, mas mais do que isso ele é importante porque informa o antropólogo que revisitar o caderno de campo torna-se fundamental para compreender onde mais ou menos tudo começou. Os itinerários, portanto, a partir daí foram sendo definidos e os palcos, pouco a pouco, revisitados ou reencenados, bem como as primeiras teias de empatia (DAWSEY, 2013) sendo tecidas.

O processo de aproximação com familiares de "Dona Braba" nesse retorno ao distrito de Alter do Chão veio a calhar para saber mais sobre tratamentos espirituais e obter mais informações sobre a pajé ("Dona Belezura”), uma vez que o antropólogo numa postura de cumplicidade relatou seus próprios "dramas” pessoais.

Sendo necessário adentrar ao palco escuro de "Dona Belezura", obtivemos nossa primeira consulta. Segue abaixo algumas anotações descritivas deste primeiro contato.

Acordei ansioso no dia 23 de julho, havia combinado com "Dona Braba” de irmos pela manhã após agendamento por telefone. No ônibus para a cidade encontrei, para minha surpresa, uma amiga cujos pro- 
jetos destinavam-se a arquitetura e modos de vida sustentável naquela vila, me acompanhou até certo ponto do trajeto. Chegamos às 09:40h no bairro onde mora "Dona Belezura", ao entrar numa casa de muro alto (no final de um beco) de alvenaria com uma varanda pequena e portão de ferro. "Dona Belezura" pareceu estar arrumando a casa, limpando cômodos e interrompeu para nos receber. Fomos apresentados, ela perguntou quem iria se consultar e "Dona Braba" me apontou. Primeiro "Dona Belezura" disse que eu iria ser atendido por outra pessoa que estava por vir e era para eu esperar, mas logo depois olhou para mim de forma desconfiada e decidiu me atender. Entrou num quarto de porta fechada e após quinze minutos pediu que entrasse. $\mathrm{O}$ ambiente era meio caótico, muitas imagens de santos, velas, apetrechos, búzios, altares, quadros grandes com uma imagem de São Sebastião e outro de Iara (metade mulher outra metade peixe), até a imagem de um pequeno Buda consegui observar de relance, eram tantos objetos ao longo de uma mesa coberta de um pano branco que era impossível de memorizá-los sem o artifício de um equipamento fotográfico. O curioso que o quarto perecia improvisado, nele se misturavam ao canto uma penteadeira, um armário com uma pilha de trecos e livros, mas no geral o cômodo com pouca luz dava um tom forte de espaço sagrado ou simbolicamente carregado. "Dona Belezura" acendeu uma vela e começou a fazer perguntas: primeiro meu nome completo, escreveu num pedaço de papel e colocou debaixo de um copo que ficava entre nós dois, no centro da mesa. Um copo transparente de água turva ao lado de uma vela vermelha e ao fundo do recipiente alguns búzios brancos, um cubo de dados e pedras não identificadas. Ao lado um cigarro grosso [charuto de tauari7] que ela logo acendeu e expelia uma fumaça densa com cheiro razoavelmente forte, assoprando a fumaça dentro do copo ela repicava com dois dedos na lateral do copo para produzir um som e sussurrava baixinho algumas palavras e frases em ritmo acelerado, algo do que pude entender como: - Peça pra Deus, peça pra Deus, peça pra Deus! Depois destes procedimentos voltou a fazer perguntas sobre minha vida amorosa e onde eu residia. Alertou-me de sentimentos de inveja que me cercavam, fez uma pausa e perguntou-me se eu estudava, voltou a me alertar que no ambiente onde eu estudava haviam pessoas que me invejam por um tipo de conhecimento que eu tinha. Disse-me para tomar muito cuidado com as amizades de que havia amizades boas, mas que havia amizades falsas e quando eu virava as costas estas pessoas não queriam meu bem e era para tomar cuidado para não emprestar roupas e objetos a ninguém. Enxergava que eu era uma pessoa de muita luz que tinha bons pensamentos e que minha vida financeira iria ficar muito boa. Perguntou-me se estava trabalhando e eu disse que não, mas ela afirmou que eu iria conseguir um emprego bom em pouco tempo. Não enxergava relacionamentos amorosos duradouros e afirmou que ainda não era hora para isso. Voltou a afirmar que eu tinha um futuro muito bom pela frente, mas algo podia atrapalhar, parece que havia algumas "judiarias" [feitiços] contra minha pessoa e enxergava também doenças dos rins, coração, fígado, mas que se eu cuidasse não me afligiria, pois, eram coisas passageiras. Voltou a perguntar com quem eu morava, eu 
respondi que estava numa pousada, mas estava só, e por fim disse que alguém não gostava de mim, que era um homem moreno, era o que enxergava através do copo. No final prescreveu banhos e disse-me onde comprá-los e da forma como deveria ser feito, após estes procedimentos de banhos eu deveria voltar lá com ela e realizar uma sessão de defumação no meu corpo. E por enquanto era isso. Ao fim fui me levantando e agradecendo, fiquei esperando que ela me cobrasse algum dinheiro, mas ela não disse nada, como "Dona Braba" havia me dito antes o valor da consulta, eu fui perguntando antes de sair do ambiente quanto custava, foi então que ela me disse o valor da vidência [foi como ela definiu aquela consulta], retirei o dinheiro do bolso e ela o pôs numa gavetinha em baixo da mesa e eu agradeci novamente (Caderno de campo, 23 de julho de 2016).

Aqui, chamamos atenção para alguns elementos subjetivos produzidos durante o ritual da vidência que não estão no relato por causa da dificuldade em descrevê-los. E também quanto ao cenário e os efeitos multissensoriais neste primeiro encontro. Quando entramos no quarto havia implícita a decisão (consciente de nossa parte) de interferir o mínimo possível no ato comunicativo da pajé, estávamos absolutamente interessados no que "Dona Belezura" tinha para dizer, qual era a tal mensagem que dali seria proferida e, mais do que isso, como e de que maneira seria feito.

Se reportarmos aos escritos de Mauss (1981), encontramos que o enunciado é o mecanismo operatório da eficácia em muitos dos rituais de povos primitivos e o ato de enunciar conectado a condições sociais particulares tem em si uma função extática ${ }^{8}$.

Ofato é que o ambiente simbolicamente carregado que nos deparamos (imagens, ornamentos e objetos de todo tipo) ativou rapidamente nossa sensibilidade estética, por assim dizer, antes de qualquer outra coisa, como se um portal (diferente) tivesse sido aberto naquele instante, acabávamos de adentrar em território alheio, como "intrusos" de uma determinada cultura, talvez seja isso que quase todos antropólogos sentem ao final de cada trabalho desenvolvido, como afirma Fonseca (2014).

No transcorrer da sessão, houveram alguns poucos diálogos mobilizados em momentos adequados já que se tornava difícil "quebrar o gelo" do momento. Nossa atenção estava toda voltada às ações práticas e aos enunciados que as acompanhavam. Aqui, concordamos com Schechner (2012, p. 84) quando diz que "os rituais mudam à medida que as circunstâncias sociais também o fazem”. Como nossa preocupação era a performance com ênfase na interação ritual, no final da sessão em que a pajé disse ter enxergado a imagem de um homem moreno no fundo do copo não sentimos a necessidade de interpelar o fato da visualização, ao contrário refletindo junto a Schieffelin (1985) e Bauman (1975) sobre as diversas poéticas verbais possíveis com suas implicações cognitivas em diferentes dimensões, pensamos na eficácia do rito também com 
receptividades distintas. Neste ponto, nossa memória logo é remetida ao inteligente conselho de Evans-Pritchard (2005) ao sugerir que:

Não podemos ter uma conversa produtiva ou sequer inteligível com as pessoas sobre algo que elas têm por auto-evidente, se damos a impressão de considerarmos tal crença como ilusão ou delírio. Se fizéssemos isso, logo cessaria qualquer entendimento mútuo e, junto com ele, toda simpatia (EVANS-PRITCHARD, 2005, p. 246),

Ainda, importante frisar que "Dona Belezura" não estava incorporada de nenhuma entidade ${ }^{9}$ ou pelo menos não demonstrou gestos em nenhum momento, isso fez com que buscássemos aportes no que Goffman $(1959,2011)$ examinou sobre as representações e interações face a face dos indivíduos no palco da vida. No sentido, de que "Dona Belezura" sabia exatamente o papel que representava naquele instante, dentro daquele contexto específico, atributo do reconhecimento social que adquiriu perante outros indivíduos. Seu proceder, portanto, tornarase inquestionável ou sob qualquer suspeita no âmbito de suas práticas de cura e sua "clientela".

\section{DO VISÍVEL AO INVISÍVEL, DO CAMPO DO POSSÍVEL À PERFORMANCE DE CURA}

O ser é túrgido de não-ser e de possivel; não é apenas aquilo que é. Merleau-Ponty

Temos que a visão em geral não consistiria, em última instância, numa espécie de delírio? Este questionamento sugere, como apontou Merleau-Ponty (1999), uma "crise de racionalidade" nas relações das ciências naturais com seu objeto de estudo.

A interpretação matemática da natureza como planaridade inerte sem fissura ou antagonismo e a ideia euclidiana de um ser-objeto independente de todo ponto de vista ou envolvimento causam enormes dificuldades para uma evolução do conhecimento ontológico das coisas e dos seres (MARTINS, 2010). Nesta perspectiva, o filósofo MerleauPonty $(1984,2004)$, em última fase de sua vida, debruçou-se sob o tema do ser (visível) e o nada (invisível) com o afã de deixar um legado de uma propedêutica a cerca de uma autêntica ontologia da natureza.

Desse modo, o pensador abandonara não só seus próprios escritos anteriores (Phénoménologie de la perception, 1945) como também o pensamento francês de sua época, principalmente as contribuições de Jean-Paul Sartre. Inspirado na experiência pictórica, o filósofo destinase a tarefa de superar a oposição entre ser e não-ser e busca trazer uma nova maneira de explorar e pensar a realidade visível.

Para começar, a experiência pictórica é a prova por excelência de que a visibilidade "comporta" a invisibilidade - não como outra visibilidade possível, ou como um possível visível para outro, quer dizer, não como 
um objeto não visto, positividade situada alhures, mas como outra dimensão, em uma palavra, negatividade. Não a negatividade lógica ou contraditória, bem entendido, mas a negatividade como verticalidade e profundidade do visível: meio que as coisas possuem de permanecer nítidas para, "embora não como aquilo que olho atualmente", fazerem-se coisas" (MERLEAU-PONTY, 1984, p. 203 apud MARTINS, 2010, p. 479).

Ora, se a visão não é um determinado modo do pensamento ou "presença de si" do sujeito vidente como afirmou o filósofo, mas sim o meio que lhe é dado de "ausentar de si" mesmo a fim de assistir "por dentro" as fissões ou segregações do ser (MERLEAU-PONTY, 1984 apud MARTINS, 2010). Procuramos “ajustar" a visão da pajé não a visão filosófica, capaz de enxergar para além das aparências, mas a capacidade (performática?) de "frequentar" o invisível para assim recompor o visível, através dos recursos que lhe são próprios, por exemplo, as incursões à morada dos encantados para obter saberes específicos.

Aperformanceritualísticanesse sentidoconstitui,fundamentalmente, o campo do visível expresso e como tal aciona os operadores da mística de cura em diversas práticas de "cura espiritual". Quanto mais sofisticada ou elaborada a performance maior é o engajamento das pessoas aflitas no seu processo terapêutico, aquele conjunto de expectativas ou participação expectativa de que fala Langdon (2007) com base em Schieffelin (1985).

O que difere os estudos de performance dos estudos clássicos do rito não são os eventos a ser analisados, mas uma alteração no direcionamento do olhar. Enquanto as análises mais clássicas do rito resultaram principalmente em interpretações do conteúdo semântico dos símbolos, as de performance chamam atenção para o temporário, o emergente, a poética, a negociação de expectativas e a sensação de estranhamento do cotidiano (SCHIEFFELIN, 1985 apud LANGDON, 2007, p. 9).

Avançando em termos comparativos, temos que, analisando cirurgias espirituais em uma Instituição Espírita Kardecista na cidade de Florianópolis (SC), Aureliano (2008) constatou quão importante são, na integração de domínios simbólicos, os elementos estéticos envolvidos para o alcance de resultados positivos na recuperação dos pacientes.

Fiquei bastante impressionada com o aparato simbólico altamente relacionado à prática biomédica naquela instituição. Sendo um centro de tratamento para pacientes com câncer e outras doenças degenerativas vinculado a um núcleo Espírita Kardecista, esperava ver ali práticas mais ligadas ao universo religioso em contraposição ao modelo biomédico alopático. Contudo, embora o elemento religioso esteja permeando fortemente os serviços de atenção à saúde ali desenvolvidos, uma forte conexão com os pressupostos biomédicos e científicos pode ser claramente observada na forma como o Centro esta organizado, na sua disposição física (divisão em enfermaria, farmácia, sala de cirurgia e 
sala de espera), no modo de vestir dos terapeutas e médiuns da casa (roupa branca, jaleco, máscaras e touca), na hierarquização das funções (médiuns operadores, médiuns doadores, instrumentadores cirúrgicos, auxiliares técnicos, leitor/a de prontuários, etc.) e na forma como as cirurgias espirituais são realizadas (em macas, com uso de iodo, gases, falsos bisturis, curativos, emissão de atestados e orientações pós-cirúrgicas) (AURELIANO, 2008, p. 3).

A dramaticidade e o caráter comunicativo das práticas ali realizadas despertaram o interesse da pesquisadora no uso do conceito de performance para analisar este campo. Enfatizamos, aqui, o aspecto visual proporcionado pela Instituição de atendimento que a autora analisou, no que tange a experiência multissensorial buscada pelos profissionais ao passo que erigiam/simulavam procedimentos cirúrgicos "invisíveis" nos seus pacientes/consulentes. Ou seja, o que estava em jogo nesta ocasião está para além da retórica de transformação (CSORDAS, 2008) que iremos discutir mais adiante, mas uma conexão direta do visível com o invisível, o espaço enigmático que liga as coisas e um relacionamento com o mundo que exige, antes de qualquer outra ideia, uma abertura de entendimento de que espírito e coisa se interpenetram e de que, como quer Merleau-Ponty (1984), o ser é túrgido de não-ser e de possível; não é apenas aquilo que é.

Semelhante questão é percebida nos processos de incorporação de caboclo em determinadas regiões do Estado do Pará. Registro realizado por Silva (2016) na região de Abaetetuba/PA referencia aspectos do modo de vida, de trabalho, de falar e de agir de uma "simples mulher" (Dona Neca) que se tornou pajé a beira do rio Urubuéua Fátima, sobre a qual a própria entidade (caboclo Tupiaçú) dá seu depoimento no trabalho de cura atuando através do corpo da pajé Dona Neca.

A minha filha (a pajé dona Neca) precisa das energias da mata, quando ela amanhece braba e não quer falar com ninguém ela vai por meio da capoeira, lá no meio dessa ilha, (rindo ele disse: é pra muito que longe essa mulher anda), lá os pássaros, os bichos e as árvores vão dando o auxílio que ela precisa. Eles falam com ela, dizem para ela o que tem que fazer e como eu vivo lá é claro que eu protejo ela lá. Vou te dizer ela volta outra pessoa, mais calma, tranquila. Isso acontece porque quando a pessoa tá na matéria de humano ele às vezes esquece que ele é uma pessoa que foi feita da mesma mão que fez as árvores, os bichos tudo quanto. Então carece de ter essa ida pro mato ficar por lá, e receber a ajuda que a mata tem pra dá. Essa ajuda faz com que ela refaça as energias de sua vida (Caboco Tupiaçú, linha de Pajelança, 24 de agosto de 2015, apud SILVA, 2016).

Nessa fala, notamos uma preocupação da entidade (caboclo tupiaçú), se assim podemos dizer, de justificar certas “idas" da pajé ao campo do invisível (morada dos encantes) para recompor energias no campo do visível (sua vida cotidiana). 
A narrativa contada, por sua vez, corrobora a tese nativa de que seres do fundo das águas, seres do mato, espíritos do ar existem e os pajés são aqueles que através de um dom especial divino conseguem realizar essas incursões para buscar auxílio em seus tratamentos de cura e, assim, poder proteger a comunidade. Tais elementos, expressam sistemas coerentes de interpretação da relação entre o homem e sua noção de saúde e doença, e como bem apontou Scopel (2007, p. 90), "o mundo da pajelança encerra uma complexidade de um campo discursivo cuja visão de mundo é centrada nas relações entre humanos, bichos encantados do fundo e espíritos do ar". Constituem, portanto, uma cosmologia em que as categorias do visível e do invisível mantêm um campo vigoroso do possível e do real "negociado".

Desta forma, retomando nosso caso, é compreensível que "Dona Braba" tenha a convicção de que "Dona Belezura" seja capaz de curar qualquer tipo de enfermidade e malefício, uma vez que seus operadores performativos criaram a poética da experiência em relevo, suas ações foram cuidadosamente observadas pela consulente, suas prescrições sistematicamente cumpridas, suas orações e benzimentos intimamente incorporados na prática de cuidados.

Dentro deste contexto, o importante foi que a cura deu certo, obteve êxito - "aí ó curado, cadê? Nunca mais teve nada!" - como explicitou "Dona Braba" em conversa informal, e que o que ela viu no copo da pajé parecia ser ou era "igual" o que saiu do nariz do menino, disto ela não tinha a menor dúvida. Todavia, durante minha estadia, "Dona Braba” não se eximiu de narrar muitos outros episódios de infortúnios que perturbaram seu filho mais velho durante muitos anos e que foi necessário um itinerário custoso em visitações a muitos pajés da região.

\section{RETÓRICA E MANIPULAÇÃO DE PROCESSOS ENDÓGENOS NA “CURA ESPIRITUAL"}

Partimos do pressuposto de que "nada se compara à força nômade da voz” (ZUMTHOR apud FERREIRA, 1997, p. 302). Embora, a sentença da citação diga respeito à performance da comunicação poética oral, neste tópico analisaremos o recurso da fala e o poder de convencimento daquele que opera esta fala quando o objetivo é curar, bem como não deixando de levar em consideração a presença-corpo.

Analisando a cura pentecostal católica a partir de dados etnográficos, Thomas J. Csordas (2008) dedica atenção cuidadosa à mobilização retórica em processos terapêuticos com pessoas espiritualmente aflitas. Um dos principais argumentos do autor explicita que os lócus da eficácia terapêutica estão nas formas e nos significados particulares - isto é, o discurso - através dos quais os processos endógenos são ativados e exprimidos" (CSORDAS, 2008, p. 49). A este recurso no tratamento espiritual, Csordas chama de Retórica de transformação. 
Trata-se de um "discurso significativo e convincente que transforma as condições fenomenológicas sob as quais o paciente existe e experiencia sofrimento ou aflição" (CSORDAS, 2008, p. 50). A retórica de transformação é constituída segundo uma formulação preliminar do autor de três tarefas anteriores e intimamente relacionadas. São elas: Retórica de Predisposição (o suplicante deve ser persuadido de que a cura é possível), Retórica de Empoderamento (o suplicante deve ser persuadido de que a terapia é eficaz) e Retórica de Transformação (o suplicante deve ser persuadido a mudar, ou seja, ele deve aceitar a mudança comportamental cognitiva/afetiva que constitui a cura dentro do sistema religioso). Assim, encadeadas essas etapas retóricas com seus respectivos graus de sofisticação e conectadas às dimensões psicossomáticas subjacentes ao sofrimento da pessoa, a transformação ocasionada pela "cura espiritual" opera em múltiplos níveis e em muitos casos sua ocorrência é entendida em termos de reintegração da pessoa curada à sua sociedade ou comunidade.

Quanto aos processos endógenos, são utilizadas técnicas semelhantes a tratamentos comuns na psicoterapia secular convencional nos quais são identificados conflitos de personalidade, de autoconfiança, sexualidade, memórias suprimidas e que neste caso são subordinadas ao significado religioso. Estes processos endógenos também podem ser estimulados por processos exógenos (acontecimentos factuais que vão exigir outras leituras) que, por sua vez, vão reorganizar a orientação de vida da pessoa suplicante, às vezes espontaneamente, às vezes inconscientemente.

No episódio relatado por "Dona Braba" é possível compreender alguns desses elementos em suas interpretações e intuições a respeito das enfermidades que acometeram não só o seu neto, mas familiares e conhecidos. Muito do que já se passou aos seus olhos, ou seja, muito do que já viu - portanto, fenômenos visíveis que vivenciou ao longo de sua vida no "sítio"10 e na cidade, e aí reside o modo como busca resolver seus problemas de natureza física e espiritual - tem, sem dúvida, a ver com um sistema de crenças que constitui um universo de discurso coerente com a "paisagem cultural" ou "sistema cultural" (caboclo amazônico) de que faz parte. Neste caso, os processos de mobilização retórica, podese ousar dizer, diferentemente da cura pentecostal carismática, são "quase" desnecessários, pois, a predisposição de "Dona Braba" segue seus preceitos e valores culturais intrínsecos.

A partir destas considerações entendemos que discursos radicalmente diferentes instauram, talvez, um modo criativo/produtivo de inteligência e ruptura com certos enquadramentos comuns da vida cotidiana. No caso da vida religiosa pode-se dizer que,

A vivência religiosa também está num processo contínuo de negociação. O que quero dizer é que a experiência molda a forma como interpretamos o mundo, num processo dialético no qual a interpretação também molda nossa experiência, numa relação de retromodelagem (SILVA, Raoni, 2016, p. 15, grifo nosso). 
Como observou Maués (2002b, 2014), todo pajé considera-se um "bom católico" 11 e reconhecemos a força da premissa colocada acima sobre a retromodelagem, pois, somente quem viveu ou vive plenamente seus dramas e sofrimentos é levado a experimentar as tecnologias mentais até seus limites e produzir, contudo, revitalizações a partir do caos ora vivenciado.

Evidentemente, este posicionamento não se restringe a lugares específicos únicos, culturas específicos ou crédulos específicos. São encontrados em diversas partes do mundo e de formas e dinâmicas diferentes, mas que podem também apresentar uma espécie de eixo comum onde transformações são seguramente observáveis. Todavia, em nosso caso analisado não descartamos a possibilidade do caráter incremental, por vezes simbiótico, como sugere Csordas (2008), dos significados religioso, espiritual e clínico em alguns casos de cura observáveis.

\section{DELIMITANDO OU ENSEJANDO A "PERFORMANCE DE CURA"}

Afim de sublinhar o que define como performance, Richard Schechner (2006) trata de recuperar a perspectiva de Ervin Goffman (1959) em um de seus escritos clássicos sobre a representação do "eu" na vida cotidiana. Para o teórico, cujos estudos têm grande aceitação nas ciências sociais produzidas no Brasil, "uma performance pode ser definida como toda e qualquer atividade de um determinado participante em uma certa ocasião e que serve para influenciar de qualquer maneira qualquer dos participantes" (GOFFMAN, 1959, p. 15). Adensando a esta perspectiva teórica, Bauman (2014) chama atenção que:

$\mathrm{Na}$ medida em que a abordagem adotada por Goffman, em relação à moldagem situada da identidade na interação, influenciou a forma da análise da interação social de modo geral, ele é reconhecido como pessoa chave no desenvolvimento de múltiplas linhas de pesquisa da linguagem na interação social seja na antropologia e na sociologia, seja na linguística. No entanto, é apropriado reconhecer, a partir dessa perspectiva, que o enquadramento orientado para performance estabelecido por Goffman não deriva de qualquer uma das disciplinas relativas à linguagem, e sim da metáfora-raiz venerável e difundida da vida como teatro (BAUMAN, 2014, p. 735, grifo nosso).

Essa abordagem dramatúrgica influenciou e influencia, até hoje, muitas das pesquisas empreendidas em certos eixos analíticos de autores brasileiros e estrangeiros, como exposto por Hartmann e Langdon (2020) e, de outo modo, Richard Bauman (2014) explora em seus argumentos os limites e alcances da obra de Goffman para a sociolinguística e para a antropologia linguística, sobretudo, a partir de algumas categorizações, tais como o enquadramento (framing), o evento de plataforma (palco) e 
a avaliação da (in)competência. Mais energeticamente, Bauman vê nas contribuições de Dell Hymes (1977) alguns referentes importantes para traçar corretivos do que estava sendo produzido anteriormente neste campo intelectual e ressaltar as dimensões criativas da interação, da poética verbal e do que viria chamar de performance enquanto exibição virtuosística.

Com sua ênfase na performance enquanto realização criativa, a proposta de Hymes pressagia um segundo e mais marcado sentido de performance que começou a coalescer na antropologia linguística concomitantemente com a noção ampla da performance como prática [...] Para aqueles folcloristas motivados de longa data pela poética verbal em seu campo, seja sob o rótulo "literatura oral", "arte verbal", "literatura folclórica” ou outro parecido, parte da atração da performance como conceito estava em sua implicação como astúcia, virtuosidade, afetação de poder, bem como a intensificação e o aprimoramento da experiência (BAUMAN, 2014, p. 732).

Em meio à diversidade de abordagens possíveis e confusões por ora, muitas das vezes, realizadas por pesquisadores precipitados ensejam a complexidade dos eventos observados (LANGDON, 2007; HARTMANN; LANGDON, 2020; BAUMAN, 2014). Nossa escolha de se alinhar às reflexões de Schechner (2006) tem um caráter simples. Para este último, "existem muitas maneiras de entender a performance. Qualquer evento, ação e comportamento podem ser examinados "enquanto" performances" (SCHECHNER, 2006, p. 49). Embora, advertindo para as diferenças no que pode ser dito que "é" performance e "enquanto" performance, o autor aponta para o fato de que,

Utilizar a categoria do "enquanto" performance tem suas vantagens. Pode-se considerar as coisas provisoriamente, em processo, enquanto elas mudam através do tempo. Em qualquer atividade humana existem normalmente muitos atores, com pontos de vista, objetivos e sentimentos diferentes e até mesmo opostos. Utilizar "enquanto" performance como uma ferramenta, pode-se olhar para as coisas que, de outra maneira, estariam fechadas para investigação. Faz-se perguntas sobre eventos da performance: como um evento se desenvolve no espaço e se manifesta no tempo? Quais as roupas ou objetos especiais que são utilizados? Quais os papéis que são desenvolvidos e como eles são diferentes, se é que são, daqueles que os atores normalmente fazem? Como os eventos são controlados, distribuídos, recebidos e analisados? (SCHECHNER, 2006, p. 49, grifo nosso).

Contudo, ainda assim o autor, já nesta época, ressalta atenção para uma questão curiosa e ao mesmo tempo importante. Se o que for considerado "é performance" tem a ver com eventos mais definidos e ligados, marcados por um contexto, por uma convenção, por um uso e por uma tradição, as distinções claras desta problemática estão se extinguindo em pleno século XXI. A avaliação de Schechner, desse 
modo, é de que se trata de uma corrente geral que direciona para a dissolução das fronteiras como alertamos no começo deste ensaio.

A internet, a globalização, e a sempre crescente presença dos meios de comunicação saturam o comportamento humano em todos os níveis. Cada vez mais as pessoas experienciam suas vidas como uma série de performances conectadas que quase sempre se sobrepõem (SCHECHNER, 2006, p. 49).

Como temos vivenciado, a circulação da informação, proporcionada por um novo regime informacional e dispositivos técnicos de todos os tipos, se intensificou de tal modo nunca antes experimentado na história da humanidade e este sentimento de "performances" ou "modos performáticos" perpassa uma miríade de ambientes sociais e interações (tensionamentos políticos e de mercado) onde as identidades são construídas, modificadas e reinventadas/revitalizadas em diversos contextos da cena global, seja sob invólucro da tradição, seja pelos dimensionamentos entrelaçados da pós-modernidade. Com ressalvas ao que os autores apreendem pelas noções de performance e performatividade, respectivamente os trabalhos desenvolvidos por Langdon (2016) e Grünewald (2017) atentam a estas últimas colocações. O primeiro refletindo como o xamanismo pode ser pensado como modo performático na manutenção da identidade dos índios Siona, no Sul da Colômbia. O segundo explorando o potencial multivocal e de afirmação étnica dos índios Pataxó, através da celebração performática de um rito de batismo, onde índios e turistas (re)criam significados.

Além disso, retomando a influência de Schechner (1985, 2006, 2012) em nossa performance de escrita e atento aos diversos gêneros de performance, o autor supracitado busca estipular algumas funções para o que a literatura tem chamado de performance de modo geral. Assim, em seu registro podemos alavancar as seguintes ideias pontuadas: as performances servem para 1) entreter, 2) construir algo belo, 3) formar ou modificar uma identidade, 4) construir ou educar uma comunidade, 5) curar, 6) ensinar, persuadir e/ou convencer, 7) lidar com o sagrado e/ ou profano.

Suas ideias discutem sobre a possibilidade de algumas performances comtemplarem bem mais de uma destas funções e a ordem de importância delas irá depender do contexto e sua variação igualmente dependerá de cultura para cultura. Rituais, cerimônias, teatro, procedimentos médicos (tradicionais ou científicos), musicais, cinema, propaganda política, militância e até revoluções podem, segundo o autor, ser moldados a partir do prisma destas funções se encarados enquanto performance. De todo modo, dentro destas sete funções Schechner (2006) ressalta que a melhor maneira de representar suas configurações seria através de esferas numa ampla rede onde se sobrepõem e interagem.

Evidentemente que nossa chave analítica é a função da cura e, neste sentido, o que opera como performático em nossos esforços de 
entender as práticas de cura tradicionais abrange os elementos estéticos, narrativos, simbólicos, psíquicos, materiais e persuasivos como os que levantados anteriormente nos relatos. Um exemplo frutífero e muito bem documentado dos entrelaçamentos possíveis, reiteramos, pode ser visto nos trabalhos de Langdon $(2010,2013,2016)$, que centralizada em pesquisas que acompanharam, nos últimos 45 anos, as transformações do xamanismo siona em modos performáticos de resiliência e sobrevivência perante contextos violentos de colonialidade, sinalizando também para efeitos de dialogicidade.

Diante do aparato globalizante do mundo moderno contemporâneo, os sistemas de trocas culturais das autoridades de cura (pajés, xamãs, curandeiros) tendem a se fortalecer ou quem sabe abrir mais espaços para aproveitadores (charlatões), talvez seria pertinente, no que cabe a antropologia, atentar para estes espaços emergentes e performáticos das expressões curativas.

\section{CONSIDERAÇÕES OU “PERTURBAÇÕES” FINAIS}

Como vimos, o modelo de persuasão evocado na práxis dos(as) pajés caboclos aliado ao aspecto visual de possessão do corpo, alteração da voz, postura, cantos, preces e gestos são acionados para criar a atmosfera espetacular de comunicação com o mundo oculto dos encantados/ bichos do fundo ou do invisível. Tal atmosfera, bem como a economia dos olhares ali, por assim dizer, administrados pelos guias espirituais é que dão sentido às "performances de cura" da pajelança cabocla e o reconhecimento e respeito social diante das comunidades e audiências. Neste sentido, a performance especificada cumpre também muitos papéis como extensão de um processo maior, como assinalou Schechner (2006):

Xamãs curam, mas eles também entretêm, educam e criam uma comunidade, e lidam com o sagrado e/ou profano. Um médico quando atende em domicílio realiza performances de encorajamento, de ensinamento e de cura. Uma missa de igreja Cristã carismática fornece cura, entretêm, mantêm a solidariedade da comunidade, invoca tanto o sagrado quanto o profano e se o sermão surtir efeito, ensina (SCHECHNER, 2006, p. 46).

Os rituais de pajelança, assim como as diversas práticas de cura espirituais, são memórias em ação (SCHECHNER, 2012). Memórias que, por sua vez, não são apenas restauradoras de valores culturais e de identidades, mas são em certa medida inventivas e adaptativas que ajudam pessoas a lidar com situações difíceis de transição que vão desde perturbações físico-emocionais a desagregações de laços sociais considerados importantes e vitais. Os tratamentos espirituais em contextos específicos podem ser vistos, paradoxalmente, como sugere Csordas (2008, p. 99), "ao mesmo tempo como formas de etnopsiquiatria e como ritos de passagem". Ou mais do que isto, como examina 
Langdon (2001), a natureza da relação doença e saúde em determinados contextos faz parte de uma construção cultural e suas representações dependem das interpretações de eventos ocorridos dentro de sistemas simbólicos específicos. As doenças, em certas ocasiões, não são vistas como processos puramente biológicos/corporais, mas como resultado do contexto cultural e da experiência subjetiva de aflição.

A doença faz parte dos processos simbólicos e não é uma entidade percebida e vivenciada universalmente. A doença é um processo experiencial; suas manifestações dependem dos fatores culturais, sociais e psicológicos que operam em conjunto com os processos psico-biológicos" (GOOD, 1994; ALVES, 1993 apud LANGDON, 2001, p. 241)

Desse modo, o processo terapêutico se caracteriza como uma negociação contínua sobre a interpretação dos sinais da doença a partir de pessoas com conhecimentos e posições de poder diferenciados (LANGDON, 2001). Visto assim, podemos sugerir que este processo não está exageradamente distante da ordem de interação social, como analisados por Goffman $(1959,2011)$, do qual os atores realizam um processo dramatúrgico em que seu desempenho de papéis e persuasão são avaliados.

Entretanto, a performance de cura enquanto comportamento restaurado é simbólico e reflexivo, suas ações e significações precisam ser decodificadas por aqueles com o conhecimento especificado, por isso Schechner adverte para o cuidado com as generalizações, uma vez que enquanto práticas concretas cada e toda performance é específica e diferente da anterior. As diferenças encenam as convenções e as tradições de um gênero, as escolhas pessoais feitas pelos sujeitos condutores, os múltiplos padrões culturais, as circunstâncias históricas e as particularidades da recepção (SCHECHNER, 2006). Todos esses elementos conjugados, nos lembra o autor, criam as realidades sociais que encerram.

Quanto aos caminhos etnográficos percorridos neste ensaio, temos afinidade com as proposições de Dawsey (2013) e Turner (2015) no que diz respeito às máscaras e palcos estranhados na própria pesquisa de campo. De um lado, o "efeito brechtiano" desdramatizante que, por final, se torna um "abalo sísmico" na cultura e na interação social. De outro, as "novas" descobertas sobre o gênero de nossos textos que não se encontram numa posição privilegiada a despeito de outros. Nas palavras de Victor Turner (2015),

Tal gênero não está numa posição privilegiada, sobretudo agora que sabemos que, na vida social, elementos cognitivos, afetivos e volitivos relacionam-se intrinsecamente e são igualmente importantes, raramente encontrados em sua forma pura, muitas vezes misturados e apenas compreensíveis pelo investigador como uma experiência vivida, uma experiência tão dele quanto das pessoas que está estudando e construída em relação à experiência destes (TURNER, 2015, p. 127, grifos do autor). 
Portanto, no teatro da vida cotidiana, o antropólogo não está isento de sua própria performance de ator social e de pesquisador que comenta a vida de outros. Dito isso, o estranhamento entre culturas é colocado em todo seu vigor nos moldes apontados por DaMatta (1978), mas não temos a certeza de que os(as) antropólogos(as) retornam do campo transfigurados em heróis ou xamãs, muito menos santos como ironiza o autor nesse texto considerado clássico.

Apreciamos a ideia de que o pesquisador "apanha" muito no campo, pois o tempo todo é colocado à prova pelos seus próprios pensamentos e atos diante do imponderável (FONSECA, 2014), e se pensarmos o alcance e os limites de suas pegadas no terreno da cultura sempre mutante, somente o tempo pode tecer os fios da experiência tão delicada que é viver com o outro, seja qual for o lugar de interesse. E, nesse sentido, a etnografia quando levada a essa abertura tende a ser a teoria em ação, como bem defendeu em vida o antropólogo Sérgio Augusto Domingues (1952-2016), o “Xàj” entre os índios que estudava. Este texto é também uma homenagem a este último, a quem dedicou uma vida à antropologia e sempre instigou e estimulou o pensamento crítico a partir do fazer etnográfico.

\section{NOTAS}

1. Vale lembrar que o(a) pajé ou xamã não costuma se assumir por esses rótulos e prefere intitular-se de curador(a) ou pela expressão, mais rara, de "surjão da terra" (MAUÉS, 2014).

2. Para uma apreciação mais aprofundada do panorama da antropologia da performance no Brasil e sua produção nas últimas décadas ver: (HARTMANN; LANGDON, 2020).

3. Muito embora aceitamos a ideia de que cada performance é única, ou seja, a cada situação há mecanismos emergentes e imediatos que diferem os atos performativos uns dos outros mediante ações imprevistas.

4. Ver: (SILVA, 2020).

5. Optamos por utilizar nomes e apelidos fictícios como forma de preservar a identidade das pessoas referidas na pesquisa.

6. "A Luffa operculata, popularmente conhecida como "buchinha-do-norte" ou "cabacinha", é uma planta medicinal muita usada no tratamento das rinites e rinossinusites. Na Europa está em medicamentos homeopáticos. Na América Latina, o fruto seco de Luffa operculata é utilizado comumente para o preparo de uma infusão que pode ser inalada ou instilada na cavidade do nariz, liberando grande quantidade de muco assim aliviando os sintomas nasossinusais" (MENON-MIYAKE, 2004, resumo).

7. (Couratari spp., Lecythidaceae)

8. Ver: (LEWIS, 1977).

9. Em documentário sobre pajelança cabocla na ilha do Marajó (PA), realizado em 1998 pela rede manchete de televisão, Zeneide Lima, reconhecida pajé e 
muito prestigiada na localidade, enfatiza que na pajelança cabocla não tem incorporação, ela afirma que é uma vibração, em suas próprias palavras: "não tem incorporação na pajelança Cabocla... tem uma vibração... é uma vibração... depois que o pajé se concentra... depois que ele começa a entrar nesse mundo... [dos encantados] é uma vibração que não tem explicação!”. Outros depoimentos de pajés caboclos na região de Autazes (AM) fazem referência aos caboclos como guias espirituais, como conselheiros que lhe acompanham em todos os trabalhos [sessões] e em diversas situações do cotidiano.

10. "Dona Braba" nasceu numa comunidade que está situada na área de proteção da Floresta Nacional do Tapajós. Geralmente quando menciona o lugar onde nasceu ela denomina-o de sítio com referências ao roçado e suas plantações.

11. “[...]embora os padres e autoridades eclesiásticas nem sempre encarem com simpatia essas crenças e práticas xamânicas; alguns, porém, numa atitude mais "moderna", chegam a demonstrar certa tolerância em relação aos pajés, cujas curas podem ser por eles pensadas como resultantes de efeitos "psicossomáticos" (Maués, 2002b, p. 53). O autor considera ainda que a pajelança cabocla seja mesmo parte do catolicismo popular e tradicional de uma parcela importante das populações rurais amazônicas.

\section{REFERÊNCIAS}

ALVES, Paulo César. A Experiência da Enfermidade: Considerações Teóricas, Cadernos de Saúde Pública, v. 9, n. 3, p. 263-271, 1993.

ANDRADE, Ugo Maia. Xamanismo e redes de relações interindígenas: Amazônia e Nordeste brasileiro. Vivência, v. 1, n. 54, p. 84-100, 14 maio 2019.

AURELIANO, Waleska de Araújo. Experiência da doença e performance: uma análise preliminar sobre o uso do paradigma de performance nos estudos das curas espirituais. Trabalho apresentado na $26^{\mathrm{a}}$ Reunião Brasileira de Antropologia, realizada entre os dias 01 e 04 de junho, 2008. Porto Seguro, Bahia, Brasil. Disponível em: $<$ http://www.abant. org.br/conteudo/ANAIS/CD_Virtual_26_RBA/foruns_de_pesquisa/ trabalhos/FP\%2004/waleska\%20ara\%C3\%BAjo.pdf>. Acesso em 10 mai. 2016.

BAUMAN, Richard. Verbal Arts as Performance. American Anthropologist, v. 77, n. 2, 1975.

BAUMAN, Richard. Fundamentos da performance. Sociedade e Estado, v. 29, n. 3, p. 727-746, 2014.

BOYER, Véronique. O pajé e o caboclo: de homem a entidade. Mana, v. 5, n. 1, p. 29-56, 1999.

CONQUERGOOD, D. Poetics, play, process, and power: the performative turn in anthropology. Text and Performance Quaterly, v.

9, n. 1, p. 82-88, 1989. 
CUNHA, Lidiane Alves; ASSUNÇÃO, Luiz de Carvalho. Benzedeiras, saberes e oralidade: a cura através do dom e da palavra. Anais... ABANNE. Fortaleza: UFC, v. 1, p. 1, 2013.

CSORDAS, Thomas J. A Retórica da Transformação no Ritual de Cura. In: CSORDAS, Thomas J. Corpo/Significado/Cura. Porto Alegre: Editora UFRGS, 2008.

DAMATTA, Roberto. O oficio de Etnólogo, ou como ter "Anthropological Blues". In: NUNES, Edson de Oliveira. A aventura Sociológica. Rio de Janeiro: Zahar, 1978.

DAWSEY, John C. Sismologia da performance: palcos, tempos, $f(r)$ icções. Cultures-Kairós, v. 7, p. 1-20, 2016.

DAWSEY, John C. De que riem os boias-frias? - Diários de antropologia e teatro. São Paulo: Terceiro Nome, 2013.

DE LIMA, Leandro Mahalem. Pajelança nas adjacências do Rio Amazonas: dimensões sociopolíticas e cosmológicas. Revista Ciências da Sociedade (RCS), v. 3, n. 5, p. 61-91, jan./jun. 2019.

DURHAM. Eunice. A pesquisa antropológica com populações urbanas: problemas e perspectivas. In: CARDOSO, Ruth. (Org.) A aventura antropológica. 2. ed. Rio: Paz e terra, 1988.

ELIADE, Mircea. O Xamanismo e as técnicas arcaicas do êxtase. São Paulo: Martins Fontes, 1998.

EVANS-PRITCHARD, Edward E. Bruxaria, oráculos e magia entre os Azande. Jorge Zahar: Rio de janeiro, 2005.

FERREIRA, Jerusa Pires. Os ofícios tradicionais. Revista USP, São Paulo, n. 29, p. 102-106, mar./maio 1996.

FERREIRA, Jerusa Pires. Posfácio. In: ZUMTHOR, Paul. Introdução à poesia oral. São Paulo: Hucitec, 1997. p. 301-308.

FONSECA, Claudia. Entrevista com a antropóloga Claudia Fonseca. 29 RBA - Natal/RN, ago. 2014. Entrevistadora: Cristhian Caje. 2014. Disponível em: <https://www.youtube.com/watch?v=L46-mYw4wRE>. Acesso em: 02 abr. 2016.

GALVÃO, Eduardo. Santos e visagens. São Paulo: Companhia Editora Nacional, 1955.

GOOD, Byron J. Medicine, Rationality and Experience: An Anthropological Perspective. Nova Iorque: Cambridge University Press, 1994.

GOFFMAN, Erving. The presentation of self in everyday life. New York: Doubleday, 1959.

GOFFMAN, Erving. Ritual de interação: Ensaios sobre o comportamento face a face. Vozes: Petrópolis, 2011.

GRÜNEWALD, Rodrigo de Azeredo. The Pataxó Baptism Rite at Aragwaksã. Vibrant, v. 14, n. 1, 2017.

HARTMANN, Luciana; LANGDON, Esther. J. Tem um corpo nessa alma: encruzilhadas da antropologia da performance no Brasil. BIB, São Paulo, n. 91, p. 1-31, 2020. 
HYMES, Dell. Breakthrough into performance. In: BEN-AMOS, Dan; GOLDSTEIN, Kenneth S. (Eds.). Folklore: performance and communication. The Hague, The Netherlands: Mouton, 1977. p. 11-74. INGOLD, Tim. Caminhando com Dragões: em direção ao lado selvagem. In: STEIL, C. A.; CARVALHO, M. (Orgs.). Cultura, Percepção e Ambiente. São Paulo: Terceiro Nome, 2012.

KOPENAWA, Davi; ALBERT, Bruce. A queda do céu: palavras de um xamã yanomami. São Paulo: Companhia das letras, 2016.

LANGDON, Esther Jean. Performance e sua Diversidade como Paradigma Analítico: a contribuição da abordagem de Bauman e Briggs. Antropologia em Primeira Mão, Florianópolis, v. 94, n. 1, p. 1-34, 2007. LANGDON, Esther Jean. A doença como experiência: o papel da narrativa na construção sociocultural da doença. Etnográfica: Revista do Centro de Estudos de Antropologia Social, Lisboa, v. 2, p. 241-260, 2001.

LANGDON, Esther Jean. Xamãs examanismos: reflexões autobiográficas e intertextuais sobre a antropologia. Revista Ilha, v. 11, n.2, p. 161-191, 2010.

LANGDON, Esther Jean. Perspectiva xamânica: relações entre rito, narrativa e arte gráfica. In: SEVERI, Carlo; LAGROU, Els. Quimeras e diálogo: xamanismo, grafismo e figuração. Rio de Janeiro: 7 Letras, 2013. p. 111-137.

LANGDON, Esther Jean. A performance da diversidade: o xamanismo como modo performático. GIS - Gesto, Imagem e Som, v. 1, n. 1, p. 9-40, 2016.

LAKATOS, Imre. Falsification and the Methodology of Scientific Research Programmes. In: LAKATOS, I.; MUSGRAVE, A. (Orgs.). Criticism and the Growth of Knowledge: Proceedings of the International Colloquium in the Philosophy of Science, London, 1965. Cambridge: Cambridge University Press, 1970. p. 91-196.

LEWIS, Ioan M. Êxtase Religioso: um estudo antropológico da possessão por espírito e do xamanismo. São Paulo: Perspectiva, 1977.

LIGIÉRO, Z. (Org.). Performance e Antropologia de Richard Schechner. Rio de Janeiro: MAUAD, 2012.

MARTINS, Paula Mousinho. Entre visível e invisível, para além do entendimento: o tema da natureza no último Merleau-Ponty. Aurora, Curitiba, v. 22, n. 31, p. 469-482, jul./dez. 2010.

MAUSS, Marcel. A Prece. Ensaios de Sociologia. São Paulo: Perspectiva, 1981.

MAUÉS, Raymundo Heraldo. A Ilha Encantada: medicina e xamanismo numa comunidade de pescadores. Belém: UFPA, 1990.

MAUÉS, Raymundo Heraldo. Catolicismo e Xamanismo: Comparação entre a cura no Movimento Carismático e na pajelança rural amazônica. Ilha, Revista de Antropologia, Florianópolis, v. 4, n. 2, p. 51-77, 2002 b. 
MAUÉS, Raymundo Heraldo. A mística em algumas formas de manifestações religiosas. Debates do NER, v. 15, p. 193-227, 2014.

MENON-MIYAKE, Mônica Aidar. Efeitos da Luffa operculata sobre o epitélio do palato isolado de rã. 2004. Tese (Doutorado) - Faculdade de Medicina, Universidade de São Paulo, 2004.

MERLEAU-PONTY, Maurice. O visível e o invisível. São Paulo: Perspectiva, 1984.

MERLEAU-PONTY, Maurice. Fenomenologia da percepção. São Paulo: Martins Fontes, 1999.

MERLEAU-PONTY, Maurice. A natureza. São Paulo: Martins Fontes, 2000 .

MERLEAU-PONTY, Maurice. O olho e o espírito. São Paulo: Cosac \& Naify, 2004.

SCOPEL, Daniel. Saúde e Doença entre os Índios Mura de Autazes (Amazonas): processos socioculturais e a práxis da auto-atenção. 2007. 146 f. Dissertação (Mestrado em Antropologia social) - Universidade Federal de Santa Catarina, 2007.

SCHECHNER, Richard. O que é performance? In: SCHECHNER, Richard. Performance studies: an introduccion. New York \& London: Routledge, 2006. p. 28-51.

SCHECHNER, Richard. Between Theater and anthropology. Filadélfia: Pensylvania University Press, 1985.

SCHIEFFELIN, Edward. Performance and the Cultural Construction of Reality. American Ethnologist, v. 12, n. 4, 1985.

SILVA, Dárnisson Viana; GRÜNEWALD, Rodrigo de Azeredo. Velhas e Novas Crenças: sobre o encontro de religiosidades em uma vila amazônica. Religião e Sociedade, Rio de Janeiro, v. 39, n. 1, p. 198-223, 2019.

SILVA, Lucielma Lobato. De simples mulher a Pajé: A constituição da pessoa a luz do ritual de preparo da pajé de Cura em AbaetetubaPA. 30a Reunião Brasileira de Antropologia, 2016, João Pessoa/PB. Políticas da Antropologia: Ética, Diversidade e Conflito, v. 1, p. 1-20, 2016.

SILVA, Dárnisson Viana. Socioantropologia da pesca artesanal no rio Tapajós: regime de informação enquanto regime de vida em uma vila de pescadores no Lago do Juá, Santarém-PA. 2020. Tese (Doutorado em Ciências Sociais) - Centro de Humanidades, PPGCS - Universidade Federal de Campina Grande, Paraíba, 2020.

SILVA, Raoni. Corpo, Cura e Emoções: Modos de cuidado e a Experiência da doença num terreiro de Candomblé/Jurema. Apresentado no $30^{\mathrm{a}}$ Reunião Brasileira de Antropologia, realizada em João Pessoa/PB, entre os dias 03 e 06 de agosto de 2016. 
TAYLOR, Diana. Traduzindo Performance [prefácio]. DAWSEY et al. (Orgs.). Antropologia e Performance. Ensaios NAPEDRA. São Paulo: Terceiro Nome, p. 9-16, 2013.

TAYLOR, Diana. Disappearing Acts. Durham: Duke University Press, 1997.

TURNER, Victor. Do Ritual ao Teatro: a seriedade humana de brincar. Trad. Michele Markowitz e Juliana Monteiro. Rio de Janeiro: Ed. UFRJ, 2015. 